This is the author's final, peer-reviewed manuscript as accepted for publication. The publisher-formatted version may be available through the publisher's web site or your institution's library.

\title{
Graphene supported plasmonic photocatalyst for hydrogen evolution in photocatalytic water splitting
}

G. P. Singh, K. M. Shrestha, A. Nepal, K. J. Klabunde, C. M. Sorensen

\section{How to cite this manuscript}

If you make reference to this version of the manuscript, use the following information:

Singh, G. P., Shrestha, K. M., Nepal, A., Klabunde, K. J., \& Sorensen, C. M. (2014). Graphene supported plasmonic photocatalyst for hydrogen evolution in photocatalytic water splitting. Retrieved from http://krex.ksu.edu

\section{Published Version Information}

Citation: Singh, G. P., Shrestha, K. M., Nepal, A., Klabunde, K. J., \& Sorensen, C. M. (2014). Graphene supported plasmonic photocatalyst for hydrogen evolution in photocatalytic water splitting. Nanotechnology, 25(26), 265701.

Copyright: (C) 2014 IOP Publishing Ltd

Digital Object Identifier (DOI): doi:10.1088/0957-4484/25/26/265701

Publisher's Link: http://iopscience.iop.org/0957-4484/25/26/265701/article

This item was retrieved from the K-State Research Exchange (K-REx), the institutional repository of Kansas State University. K-REx is available at http://krex.ksu.edu 


\title{
Graphene supported plasmonic photocatalyst for Hydrogen evolution in Photocatalytic water splitting
}

\author{
G. P. Singh, ${ }^{1,2} *$ K. M. Shrestha, ${ }^{3}$ A. Nepal, ${ }^{2}$ K. J. Klabunde ${ }^{3}$, C. M. Sorensen $^{2}$ \\ ${ }^{1}$ Centre for Nanotechnology, Central University of Jharkhand, Ranchi-834205, Jharkhand, India \\ ${ }^{2}$ Department. of Physics, Kansas State University, Manhattan, KS 66506, USA \\ ${ }^{3}$ Department of Chemistry, Kansas State University, Manhattan, KS 66506, USA
}

\begin{abstract}
It is well known that the noble metals nanoparticles show active absorption in the visible region due to the existence of the unique feature known as surface plasmon resonance (SPR). Here we report the effect of plasmonic Au nanoparticles towards the enhancement of the renewable $\mathrm{H}_{2}$ evolution

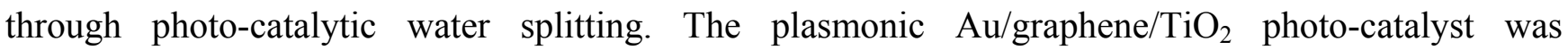
synthesized in two steps: first the graphene $/ \mathrm{TiO}_{2}$ nanocomposites were developed by the hydrothermal decomposition process; thereafter the Au was loaded by photodeposition. The plasmonic Au and the graphene as co-catalyst effectively prolong the recombination of the photogenerated charges. This plasmonic photocatalyst displayed enhanced photo-catalytic $\mathrm{H}_{2}$ evolution for water splitting in the presence of methanol as a sacrificial reagent. The $\mathrm{H}_{2}$ evolution rate from the Au/graphene co-catalyst was about 9 fold higher than that of a pure graphene catalyst. The optimal graphene content was found to be $1.0 \mathrm{wt} \%$, giving a $\mathrm{H}_{2}$ evolution of $1.34 \mathrm{mmol}$ (i.e. $268 \mu \mathrm{molh}^{-1}$ ), which exceeded the value of $0.56 \mathrm{mmol}$ (i.e. $112 \mu \mathrm{molh}^{-1}$ ) observed in pure $\mathrm{TiO}_{2}$. This high photo-catalytic $\mathrm{H}_{2}$ evolution activity is due to the deposition of $\mathrm{TiO}_{2}$ on graphene sheets, which acts as an electron acceptor to efficiently separate the photogenerated charge carriers. However, the Au loading enhanced the $\mathrm{H}_{2}$ evolution dramatically and achieved a maximum value of $12 \mathrm{mmol}$ (i.e. $2.4 \mathrm{mmolh}^{-1}$ ) with optimal loading of 2.0 $\mathrm{wt} \% \mathrm{Au}$ on graphene/ $\mathrm{TiO}_{2}$ composites. The enhancement of $\mathrm{H}_{2}$ evolution in presence of $\mathrm{Au}$ is due to the SPR effect induced by visible light irradiation which boosts the energy intensity of the trapped electron as well as active sites for photo catalytic activity.
\end{abstract}

Keywords: Graphene, $\mathrm{TiO}_{2}$, Hydrogen, Water-splitting

\section{Introduction}

Improvement in hydrogen $\left(\mathrm{H}_{2}\right)$ evolution through photo-induced water splitting is emerging as a viable choice to meet the requirement of clean sustainable energy for various practical applications and resolve environmental problems [1-5]. The sustainable and efficient evolution of $\mathrm{H}_{2}$ requires a stable 
and efficient catalytic system for water oxidation (to form molecular oxygen), and this is the more challenging half reaction in the overall water splitting [6,7]. After intensive study, the semiconductors having a conduction band edge sufficiently more negative than the reduction potential of water (or protons) and remain stable in contact with water have been considered as appropriate catalyst materials. The interfacial area between the catalyst and liquid water should also be large enough to allow water dissociation to take place at a high specific rate $[7,8]$. Titanium dioxide $\left(\mathrm{TiO}_{2}\right)$ has been found as a good photo-catalyst among semiconductors for $\mathrm{H}_{2}$ evolution due to its wide band gap (3.2 eV), appreciable photo-activity under UV light irradiation, stability, non-toxicity, inexpensive and large availability $[9,10]$. However, it is $\mathrm{TiO}_{2}$ is poorly active for $\mathrm{H}_{2}$ production due to fast electron-hole recombination and large over-potential characteristics. The most promising and viable ways to overcome these drawbacks are the deposition of metal nanoparticles on bare $\mathrm{TiO}_{2}$ or the self-doping of $\mathrm{TiO}_{2}$ with compatible materials [11-14].

Recently, Graphene, a two-dimensional $\mathrm{sp}^{2}$ network of carbon, has been shown to possesses outstanding mechanical strength, thermal conductivity $\left(5000 \mathrm{Wm}^{-1} \mathrm{~K}^{-1}\right)$, and exhibits an exceptionally high theoretical specific surface area $\left(2600 \mathrm{~m}^{2} \mathrm{~g}^{-1}\right)$, high transparency, structural flexibility, chemical stability and superior charge carriers mobility $\left(200000 \mathrm{~cm}^{2} \mathrm{~V}^{-1} \mathrm{~s}^{-1}\right),[10,15-17]$. Based on these extraordinary properties, graphene has been considered another useful material for the $\mathrm{H}_{2}$ production because it (i) provides a support for anchoring well-dispersed metallic or oxide nanoparticles, (ii) works as a highly conductive matrix for enabling good contact throughout the matrix, (iii) induces an easy electron transfer from the conduction band of semiconductors to graphene because of the large energy level offset formed at the interface, leading to an efficient charge separation, and (iv) acts as an efficient co-catalyst for $\mathrm{H}_{2}$ evolution due to large specific surface area and superior electron mobility [18-22]. However, the $\mathrm{H}_{2}$ evolution activity of graphene as co-catalyst is still limited and needs to be further enhanced from the view point of practical applications and commercial benefits.

In this context, a few bimetallic systems, namely $\mathrm{Au} / \mathrm{Pd}$ core-shell nanoparticles, polymer protected $\mathrm{Pt} / \mathrm{Ru}$ bimetallic clusters, bimetallic $\mathrm{Au} / \mathrm{Pt}$ systems and nonmetal elements such as $\mathrm{S}, \mathrm{N}, \mathrm{C}$ immobilized on $\mathrm{TiO}_{2}$ have been investigated for $\mathrm{H}_{2}$ production through photo-induced water splitting $[10,13,23-26]$. It is observed that the heterogeneous catalysts account good performances in hydrogenation reactions due to longer electron mobility as well as surface ensemble effects. In addition, the versatile properties of $\mathrm{Au}$ nanoparticles such as the capacity of altering the physicochemical properties, surface plasmon resonance (SPR), conductivity, and redox behavior have proved itself as a useful material for the range of applications leading to improvement in the catalytic properties [27]. 
In this paper we report the properties of visible region SPR responsive Au nanoparticle loaded graphene supported $\mathrm{TiO}_{2}$ nanocomposite photo-catalysts for enhanced $\mathrm{H}_{2}$ evolution through water splitting in presence of methanol as a scavenger. The loading of $\mathrm{Au}$ on the graphene and $\mathrm{TiO}_{2}$ surface is done in order to use the full UV-Visible spectrum region of light to produce appreciable $\mathrm{H}_{2}$ from the water and methanol mixture.

\section{Experimental procedure for the preparation of Au loaded graphene supported $\mathrm{TiO}_{2}$ nanocomposites as a photocatalyst}

\subsection{Synthesis of graphene oxide sheets (GOs):}

GOs were synthesized from commercial graphite flakes by using a well-known modified Hummers method [28]. In a typical process, a mechanically mixed mixture of graphite flakes (2 g) and $\mathrm{NaNO}_{3}(1 \mathrm{~g})$ was put into concentrated $\mathrm{H}_{2} \mathrm{SO}_{4}(46 \mathrm{~mL}, 18 \mathrm{M})$ at $0^{\circ} \mathrm{C}$ in ice bath, and then $\mathrm{KMnO}_{4}(6 \mathrm{~g})$ was slowly added to the above solution with vigorous stirring in proportions to keep the reaction temperature below $20^{\circ} \mathrm{C}$ in the ice bath to produce the graphite oxide. The reaction mixture was warmed to $35^{\circ} \mathrm{C}$ in an oil bath and maintained at this temperature with stirring until a brown color paste was formed $(\sim 2 \mathrm{~h})$. After that, the reaction was terminated slowly by adding water $(92 \mathrm{~mL}) \mathrm{which}$ increased the temperature to $95-98^{\circ} \mathrm{C}$, and the resulting suspension was maintained at this temperature for $20 \mathrm{~min}$. The suspension was then diluted to approximately $280 \mathrm{~mL}$ by the addition of water followed by treatment with $\mathrm{H}_{2} \mathrm{O}_{2}(9 \mathrm{~mL}, 35 \%)$. Upon treatment with peroxide, the suspension turned bright yellow. After cooling in air, the suspension was filtered and washed with aqueous $\mathrm{HCl}(1: 10$, $37 \%$ ) and then with water. The obtained solid was graphite oxide. The graphite oxide was further exfoliated by sonicating in water for $2 \mathrm{~h}$, and then centrifuged at $4500 \mathrm{rpm}$ for $20 \mathrm{~min}$. The supernatant was decanted and dried with a rotovapor at $40^{\circ} \mathrm{C}$ followed by vacuum drying at $40^{\circ} \mathrm{C}$ for $12 \mathrm{~h}$. The obtained powder was GO.

\subsection{Preparation of $\mathrm{rGO}^{\mathrm{TiO}} \mathrm{T}_{2}$ composites}

Different amounts of $\mathrm{TiO}_{2}(\mathrm{P} 25)$ decorated with reduced graphene oxide (rGO) nanosheets were prepared via a hydrothermal synthesis process. In this process, the selective volumes of exfoliated aqueous GO suspension (stock solution, $0.5 \mathrm{mg} / \mathrm{ml}$ ) were re-exfoliated in a solution of distilled water $(80 \mathrm{~mL})$ and ethanol $(40 \mathrm{~mL})$ by ultrasonic treatment for $2 \mathrm{~h}$. Then, the $1 \mathrm{~g} \mathrm{TiO}_{2}$ powder was slowly dispersed into the GO solution under stirring and allowed for stirring another $2 \mathrm{~h}$ to get a homogeneous suspension. The suspension was transferred in a $100 \mathrm{~mL}$ Teflon-sealed autoclave containing $60 \mathrm{ml}$ suspension. The hydrothermal treatment was carried out at $180^{\circ} \mathrm{C}$ for $5 \mathrm{~h}$ for simultaneously reduction of GO into rGO in presence of ethanol and the anchoring of $\mathrm{TiO}_{2}$ on the rGO active sites. Finally, the 
resulting composite was recovered by rinsing with deionized water followed by ethanol several times, and dried in an oven at $40^{\circ} \mathrm{C}$ for $12 \mathrm{~h}$. The weight percentages of $\mathrm{GO}$ to $\mathrm{TiO}_{2}$ were $0,0.25,0.5,1.0,2.0$ and $4.0 \%$, and the composites were labeled as $\operatorname{rGOXT}$ (where $\mathrm{X}=0,0.25,0.5,1.0,2.0$ and 4.0).

\subsection{Preparation of Au loaded $\mathrm{rGO}^{-\mathrm{TiO}_{2}}$ composites}

A photo-deposition process was used to prepare the Au loaded rGOXT composites in the presence of UV irradiation. The photo-deposition was carried out in a well-shaped double wall quartz reactor. Firstly the rGOXT composites of $200 \mathrm{mg}$ wereas dispersed in $300 \mathrm{ml}$ water and methanol solution $(\mathrm{v} / \mathrm{v}=2: 1)$, thereafter an appropriate amount of $\mathrm{AuCl}_{3}$ precursor solution was injected dropwise with a through syringe into reactor. The reactor was sealed with a rubber septum and degassed by purging Ar in the solution for $30 \mathrm{~min}$ at atmospheric pressure. After degassing, the mixture was irradiating using a high pressure $450 \mathrm{~W} \mathrm{Hg}$ lamp for $1 \mathrm{~h}$ under vigorous stirring to obtain Au loaded rGOXT composites. These samples are labeled as AuYrGOXT (where $\mathrm{X}=1.0$ and $\mathrm{Y}=0.5,1.0,2.0,3.0$, 4.0, 5.0, and $8.0 \mathrm{wt} \%)$.

\section{Characterizations}

\subsection{Structural Characterization}

Phase analysis was performed by using powder X-ray diffraction (XRD) with a Bruker D8Advance X-ray diffractometer with monochromatized $\mathrm{Cu} \mathrm{K} \mathrm{K}_{\alpha}$ radiation $(\lambda=1.5418 \AA)$. Transmission electron microscopy (TEM) images were collected on a Philips microscope with an accelerating voltage of $100 \mathrm{kV}$. Diffuse reflectance UV-visible spectra were obtained over the 200-800 nm range using $\mathrm{BaSO}_{4}$ as a reference using a Carry 500 Diffuse reflectance UV-visible spectrophotometer (DRUVS). Diffuse reflectance FTIR spectra were recorded via a Nexus 670 Nicolet spectrophotometer,

Agilent Technology, USA over a range 500-4000 $\mathrm{cm}^{-1}$. The room temperature Raman spectra were obtained with an iHR550 Raman spectrophotometer, Horiba Jobin Yvon with a HeNe laser (632.8 nm) as the excitation source. Brunauer-Emmet-Teller (BET) measurements of surface area and pore size distribution of nanocomposites were determined using a Quantachrome NOVA $1200 \quad \mathrm{~N}_{2}$ gas adsorption/desorption analyzer at liquid nitrogen temperature.

\subsection{Photo-catalytic hydrogen evolution from water splitting}

The photo-catalytic $\mathrm{H}_{2}$-evolution reaction was carried out in a well-shaped double wall quartz reactor (outer diameter $50 \mathrm{~mm}$ ) connected to a closed gas circulation, evacuation and cooling system $[29,30]$. A high pressure, $450 \mathrm{~W} \mathrm{Hg}$ lamp was used as a UV-visible light irradiation source. In a typical experiment, $200 \mathrm{mg}$ of rGOXT nanocomposite photo-catalyst was suspended in a $340 \mathrm{~mL}$ of 
aqueous solution containing 10\% methanol scavenger by volume. Prior to the photo-catalytic reaction, the suspension of the catalyst was dispersed in an ultrasonic bath for $10 \mathrm{~min}$, and then purged with Ar through the reactor for $30 \mathrm{~min}$, to completely remove the dissolved oxygen and ensured that the reactor was in an anaerobic condition. A continuous magnetic stirrer was applied at the bottom of the reactor in order to keep the photo-catalyst particles in suspension during the whole experiment. The photocatalyst was irradiated by inserting a lamp into the center of the reactor. The temperature of the reactant solution was maintained at room temperature by providing a flow of cooling water through the outer wall of the reactor during the photo-catalytic reaction. The reaction was carried out for $5 \mathrm{~h}$, and the reaction products were analyzed by GC using an online sampling loop at intervals of $1 \mathrm{~h}$. The GC (GOW-MAC 580 model) system was equipped with All Tech molecular 80/100 sieve 5 A column and a thermal conductivity detector, with Ar flowing as the carrier gas. The similar process is also used for the $\mathrm{Au}$ loaded rGOXT samples for $\mathrm{H}_{2}$ evolution.

\section{Results and Discussion}

\subsection{Phase analysis}

Powder XRD patterns of GO and rGOXT composites (where $\mathrm{X}=0,0.25,0.5,1.0$ and 2.0) are shown in Fig. 1. The XRD peak observed in Fig. 1(a) at about $9.8^{\circ}$ corresponds to the (002) interlayer spacing $(d)$ of $0.90 \mathrm{~nm}$, which fairly matches with the value reported in the literature for GO [22] whereas the XRD patterns of rGOXT composites shown in Fig. 1(b-e) represent well defined crystalline peaks of both anatase and rutile phases of $\mathrm{TiO}_{2}$. These peaks are consistent with the JCPDS no. 21-1272 for anatase and 21-1276 for rutile (see Fig. S1). It is evident from the XRD that no characteristic diffraction peaks of reduced graphene (rGO) are observed in all composite samples $\{($ Fig. 1(b-e)\}. This might be because of the destruction of the regular stacking of GO through the reduction process under the hydrothermal conditions and the low amount of rGO or relatively low diffraction intensity of graphene [31,32]. In addition, the change in the crystal structure of $\mathrm{TiO}_{2}$ after hybridization with GO nanosheets is observed to be almost negligible. 


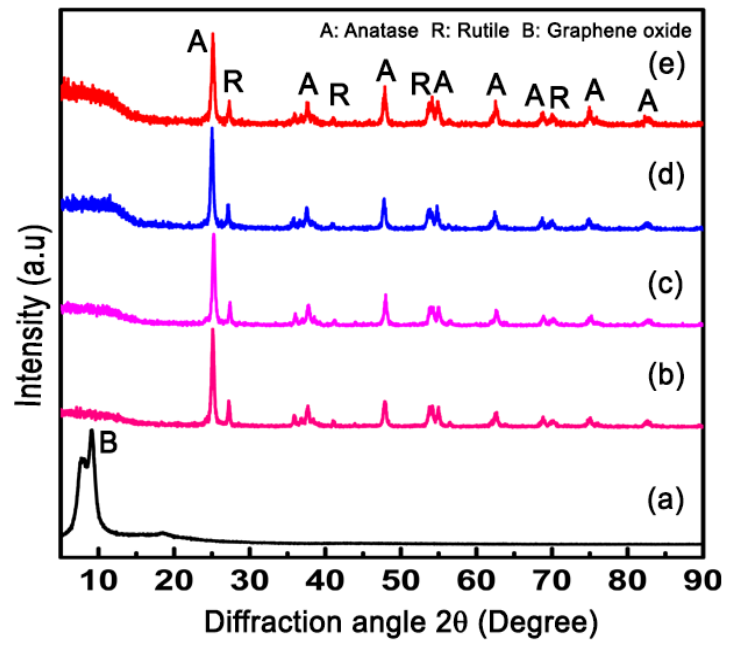

Figure 1: Powder X-ray diffraction patterns of (a) GO, (b) rGO0.25T, (c) rGO0.5T, (d) rGO1T and (e) rGO2T samples.

The diffraction patterns of the different Au contents (0.5-8.0 wt\%) loaded rGO1T composites are shown in Fig. 2. In all samples $\{$ Fig. 2(b-h)\}, the shift in peaks positions shifted towards the higher diffraction angles is observed, to imply a results reduction in $d$-value after incorporation of $\mathrm{Au}$. The reduction of $d$-values represents the $\mathrm{Au}$ loading on $\mathrm{TiO}_{2}$ which is expected in the present experiment. In sample Au0.5rGO1T \{Fig. 2(b)\}, no Au peak is detected in XRD which indicates the fine dispersion of $\mathrm{Au}$ species on the surface of rGO1T composites. However, the clear signature of the Au peaks are observed in the sample containing Au contents from 1.0 to $8.0 \mathrm{wt} \%$ in rGO1T $\{$ Fig. 2(c-h) $\}$ which shows that Au nanoparticles have been photo-deposited on rGO1T after UV light irradiation for $1 \mathrm{~h}$.

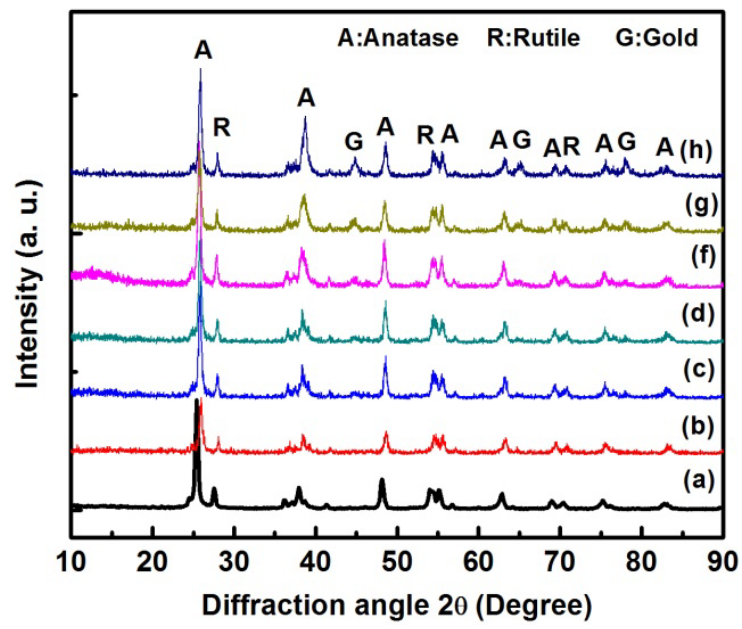

Figure 2: Powder X-ray diffraction patterns of (a) 0, (b) 0.5, (c) 1.0, (d) 2.0 (e) 3.0 (f) 4.0 and (g) 5.0 and (h) $8.0 \mathrm{wt} \%$ of Au loaded rGO1T samples. 


\subsection{Raman spectra analysis of graphene and its composites}

The crystalline quality and the degree of disorder of the carbon in graphene structure after hydrothermal decompositions of pure and composite form were analyzed by Raman spectroscopy. Significant structural changes occurred during the hydrothermal treatment of GO. The Raman spectra of $\mathrm{GO}, \mathrm{TiO}_{2}$ and rGOXT composites (where $\mathrm{X}=0,0.25,0.5,1.0$, and 2.0) are demonstrated in Fig. 3(a-f). The two typical Raman bands in GO are observed at around 1351 and $1597 \mathrm{~cm}^{-1}$ sshown in Fig. $3(\mathrm{a})\}$. The band at around $1351 \mathrm{~cm}^{-1}$ is common for disordered $\mathrm{sp}^{2}$ carbon and is known as D-band [33, 34]. The another band at around $1597 \mathrm{~cm}^{-1}$ is close to well-ordered graphite and is often called the Gband or $\mathrm{E}_{2 \mathrm{~g}}$ mode $[32,33]$. In the case of rGO0T $\{$ Fig. 3(b) $\}$, the anatase phase shows major Raman bands at $144,395,515$, and $638 \mathrm{~cm}^{-1}$. These bands can be attributed to the five Raman-active modes of the anatase phase with the symmetries of $\mathrm{E}_{\mathrm{g}(1)}, \mathrm{B}_{\lg (1)}, \mathrm{A}_{\lg }+\mathrm{B}_{\lg (2)}$, and $\mathrm{E}_{\mathrm{g}(2)}$, respectively. The typical Raman bands due to rutile phase appear at 143 (superimposed with the $144 \mathrm{~cm}^{-1}$ band due to anatase phase), 235, 445, and $612 \mathrm{~cm}^{-1}$ can be ascribed to the $B_{1 \mathrm{~g}}$, two-phonon scattering, $\mathrm{E}_{\mathrm{g}}$, and $\mathrm{A}_{1 \mathrm{~g}}$ modes of rutile phase respectively [35-37].

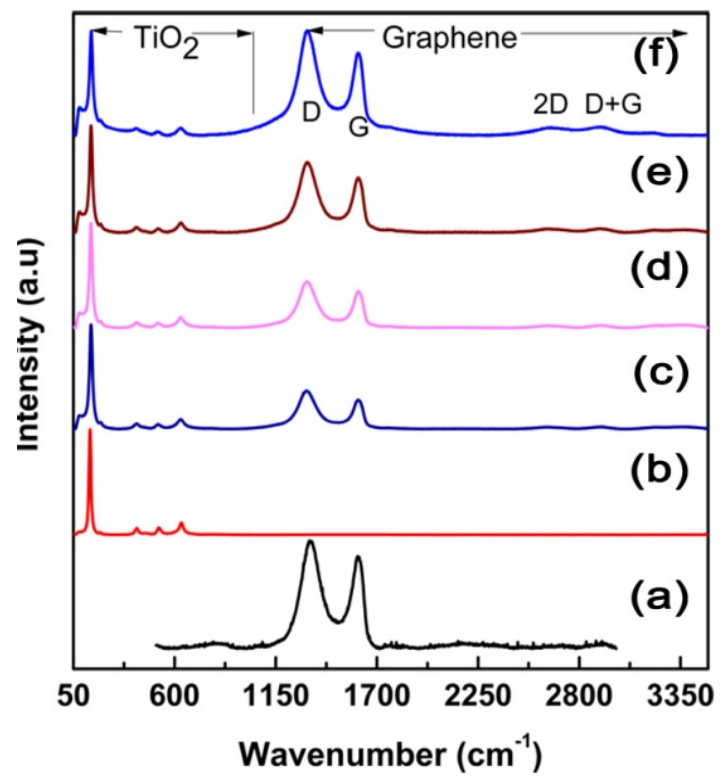

Figure 3: Raman spectra of (a) GO, (b) rGO0T, (c) rGO0.25T, (d) rGO0.5T, (e) rGO1.0T and (f) rGO2.0T samples.

All the Raman bands for anatase and rutile phases are retained in rGOXT as shown in Fig. 3(ce). In the present study, the Raman analysis reveals the shift in G-band from 1597 to $1587 \mathrm{~cm}^{-1}$ and the D-band from 1351 to $1321 \mathrm{~cm}^{-1}$ after $\mathrm{TiO}_{2}$ loading. These shifts are consistent with the previous reports [38,39]. Moreover, the 2D band at around $2692 \mathrm{~cm}^{-1}$ is also observed (see Fig. S2), indicating the reduction of $\mathrm{GO}$ and the formation of graphene structure. The peak position of the $2 \mathrm{D}$ band is similar to 
that of a monolayer graphene [40,41]. Furthermore, the small variation in the ratio of intensity of Dband to that of G-band $\left(\mathrm{I}_{\mathrm{D}} / \mathrm{I}_{\mathrm{G}}\right)$ (see Table S3) of rGOXT in comparison to that of GO indicates the decrease in the average size of the in-plane $\mathrm{sp}^{2}$ domains upon reduction of the exfoliated GO and this confirms that the rGOXT composites as $\mathrm{TiO}_{2}$ loaded graphene sheets $[35,42]$.

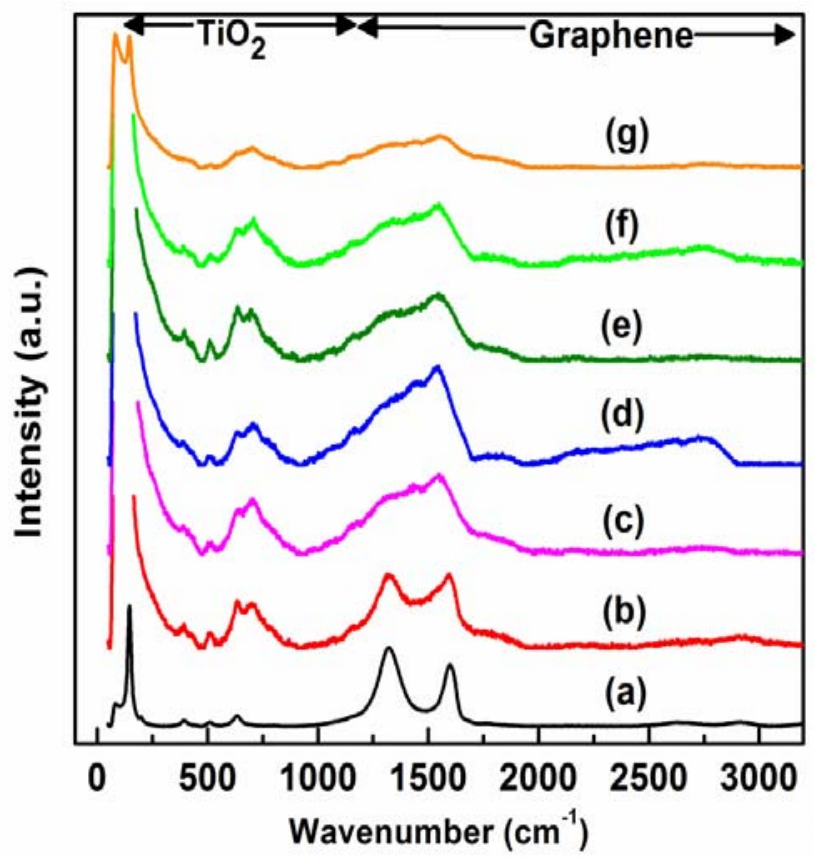

Figure 4: Raman spectra of (a) 0, (b) 0.5, (c) 1.0, (d) 2.0 (e) 3.0 (f) 5.0 and (g) 8.0 wt\% of Au loaded rGO1T samples.

Figure 4 (See Fig. S4 and S5) shows the Raman spectra of the nanocomposites with different Au loadings. A small amount of Au loading (0.5 wt.\%) significantly enhances the Raman intensity of $\mathrm{TiO}_{2}$ bands. The absorption at $144 \mathrm{~cm}^{-1}$ indicates an anatase crystalline phase structure [43]. In Au2rGO1T samples, intensity of anantase peak is enhanced by about two fold at the nanohybrid junction points because of the localized SPR from gold nanostructures (See Fig. S5). When the Au loading is increased from 0.5 to $2.0 \%$, the absorption becomes broader and stronger and shifts positively in position by $5 \mathrm{~cm}^{-1}$. This suggests increased crystalline defects within the phase [43]. Such defects may favor capturing photo-electrons and inhibiting charge recombination. Meanwhile, Au nanoparticles embedded within the structure may also serve as an electron conductor, which facilitates photo-electron transfer to surface and further reduce the probability of charge recombination [44]. When $\mathrm{Au}$ content is further increased from 2.0 to $8.0 \%$, the decrease in Raman peak intensity was observed. In addition, the $\mathrm{Au}$ loaded rGO1T nanocomposites shows the reduction in D-band and broadening in G-band with respect to rGO1T, which is consistent with previous reported results. The Au loading would cause broadening in G-band due to the electron-phonon coupling [45]. The intensity 
ratio of $\mathrm{I}_{\mathrm{D}} / \mathrm{I}_{\mathrm{G}}$ is often used as a measure of defect levels in graphitic systems. The ratio of $\mathrm{I}_{\mathrm{D}} / \mathrm{I}_{\mathrm{G}}$ is decreased from 1.28 to 0.48 up to $2.0 \mathrm{wt} \% \mathrm{Au}$ (see Table S3) indicating the increase in size of the $\mathrm{sp}^{2}$ domain during the UV treatment.

\subsection{Structural Observation}

Figure 5 (see Fig. S6) shows the TEM images of the rGO, $\mathrm{TiO}_{2}(\mathrm{rGO}$ T), rGO0.5T, rGO1T, rGO2T and rGO5T samples. In Fig. 5(a), a crumpled micrometre-long two-dimensional morphology of rGO sheet is observed after the hydrothermal treatment of GO in presence of ethanol. The crumpling in graphene sheet is due to the retention of a thermodynamically stable three-dimensional structure in localized region from the thermodynamically unstable two-dimensional sheet grown without substrate $[33,34]$. Moreover, the size of the $\mathrm{TiO}_{2}$ nanoparticles is normally in the range of 10-20 $\mathrm{nm}$ (Fig. 5b), which is consistent with crystallite size of 10-18 nm calculated from the XRD \{Fig.S1\}.

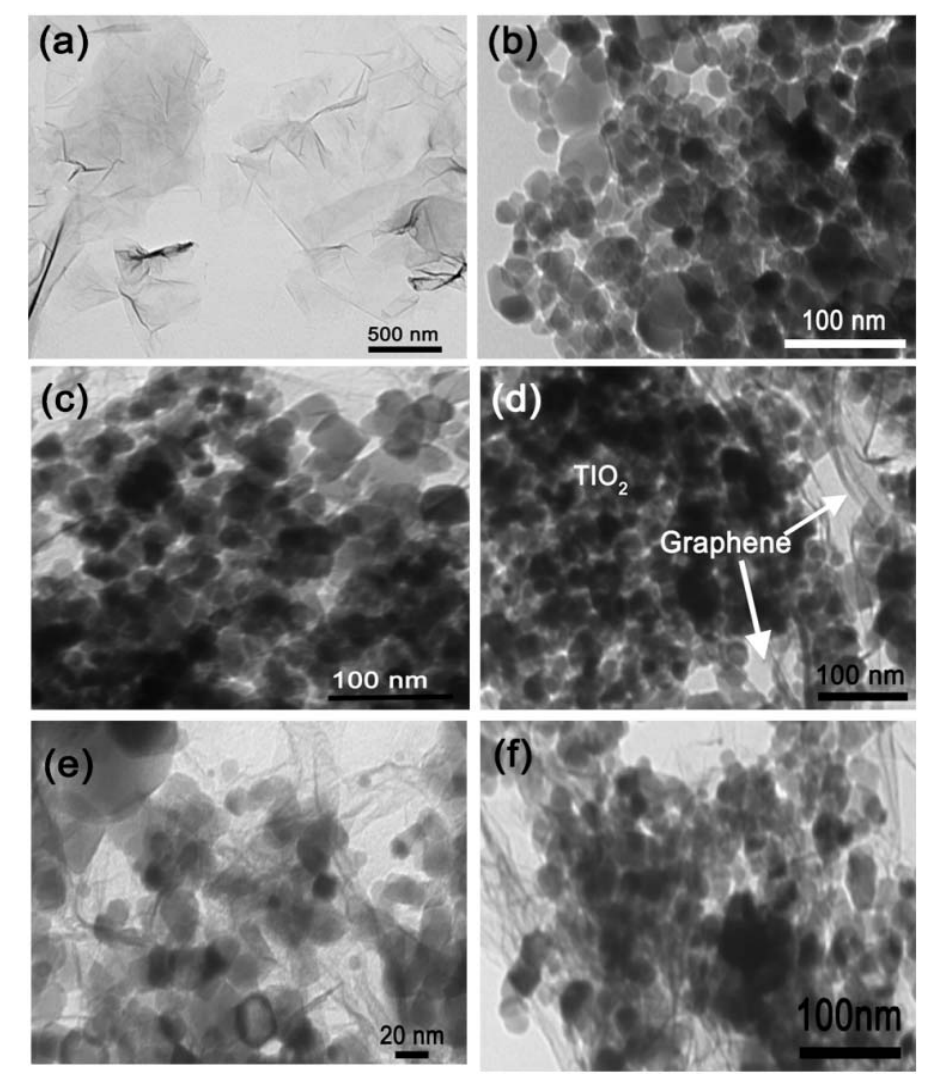

Figure 5: TEM images of (a) rGO, (b) rGO0T, (c) rGO0.5T, (d) rGO1T, (e) rGO2T and (f) rGO5T samples.

Figure 5(c and d) shows that the rGO provides good support for the densely distributed $\mathrm{TiO}_{2}$ nanoparticles on its surface. The dense distribution and loading of $\mathrm{TiO}_{2}$ nanoparticles on rGO is due to interfacial interaction and preferential heterogeneous nucleation between the hydrophilic functional 
groups (e.g., $-\mathrm{OH},-\mathrm{COOH}$ ) attached with $\mathrm{GO}$ and the hydroxyl groups on $\mathrm{TiO}_{2}$. Furthermore, the heterogeneous nucleation due to different nucleation growth rate of hydrophilic functional and hydroxyl groups can also alleviate the crumpling and agglomeration of graphene nanosheets in localized region. This intimate interaction facilitates an easy transfer of electrons from $\mathrm{TiO}_{2}$ nanoparticles to graphene sheets during the photo-excitation process. Moreover, the Fig. 5(e and f) shows that the $\mathrm{TiO}_{2}$ nanoparticles are well covered from the rGO sheets.
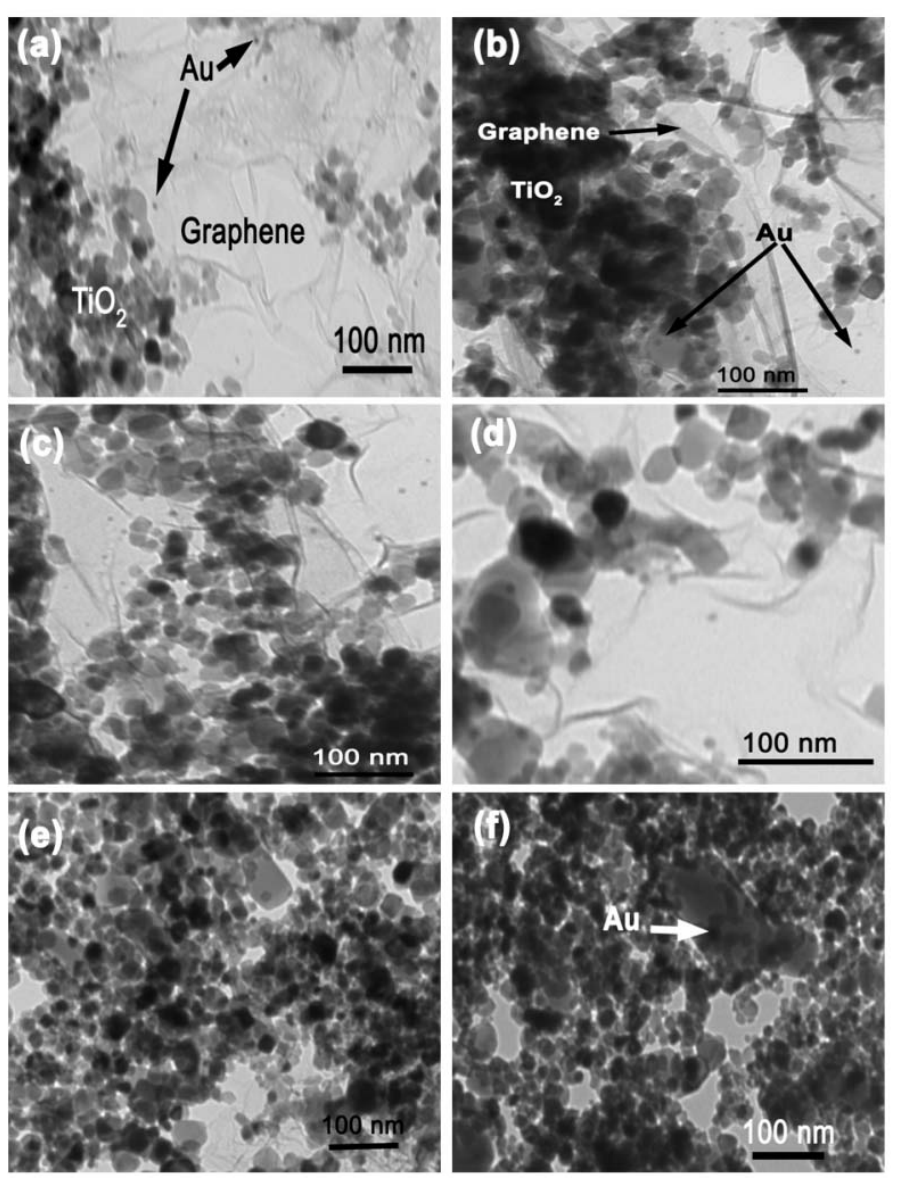

Figure 6: TEM images of Au contents of (a) 1.0, (b) 2.0, (c) 3.0, (d) 4.0, (e) 5.0 and (f) $8.0 \mathrm{wt} \%$ loaded on rGO1T samples.

The TEM image of photo-deposited of different Au contents (with contents 1.0-8.0 wt\%) on the rGO1T samples is shown in Fig. 6 (and S7). The images revealed that Au is well loaded and dispersed on the $\mathrm{TiO}_{2}$ /graphene surface. The Au particles of mean size in the range of 3-8 nm of nearly spherical shape were observed as dark spots having obvious contrast with the $\mathrm{TiO}_{2}$ /graphene support as shown in Fig. 6(b). With increasing the Au contents, the size of the Au particles are increased which is obvious. The Au loading of $8.0 \mathrm{wt} \%$ shows the cluster formation of $\mathrm{Au}$ nanoparticles on $\mathrm{TiO}_{2}$ and $\mathrm{rGO}$ surface 
in Fig 6(f). Here, the crumpled rGO sheet enables the formation of an interlocked network with Au and $\mathrm{TiO}_{2}$. Akhavan has also found the similar kind of interlocked network formation in photo-degraded graphene oxide sheets at the tip of $\mathrm{ZnO}$ nanorods [46]. This kind of nanocomposites' nanolayer is desirable for the enhancement of the interfacial interaction between the co-catalysts with $\mathrm{TiO}_{2}$ and for the increment of the number of catalytically active sites on the co-catalyst surface.

\subsection{Specific surface area analysis}

The nitrogen adsorption-desorption isotherms analysis was performed to investigate the porosity and BET surface area of the prepared samples. The TEM images \{Fig. 5(b and d\} show an assembly of numerous particles with large open packing. The adsorption-desorption isotherms of the pure $\mathrm{TiO}_{2}(\mathrm{rGO} 0 \mathrm{~T})$ and $\mathrm{GO}$ supported $\mathrm{TiO}_{2}(\mathrm{rGO} 1 \mathrm{~T})$ are portrayed in Fig. 7 (a and b), respectively. Nitrogen adsorption-desorption isotherms curves of these two samples show similar shaped hysteresis loops at relative pressure $\left(\mathrm{P} / \mathrm{P}_{\mathrm{o}}\right)$ close to unity. According to IUPAC, these curves fairly display the typical type IV isotherms and type H3 hysteresis loops which is the characteristics feature of the mesopores [47-49]. Here, the mesopores formation is associated with a presence of aggregates of platelike particles, giving rise to slit-like pores, [47] which is consistent with the TEM results \{Fig. 5(b and d) $\}$.

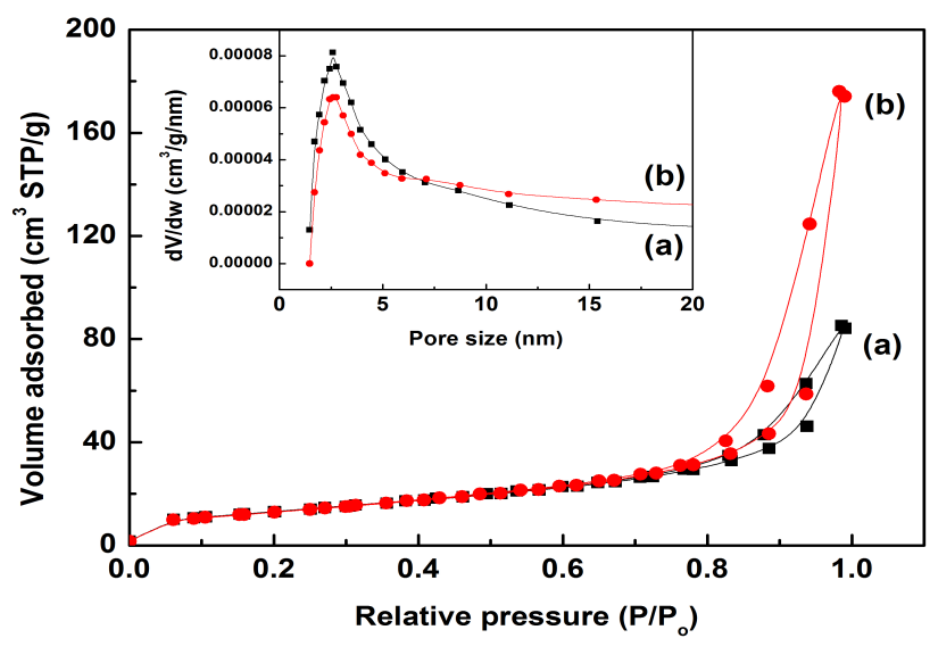

Figure 7: BET isotherm of (a) rGO0T and rGO1T samples

The pore size distribution curves of both samples (displayed in inset of Fig. 7) are broad in the range of 2 to over $100 \mathrm{~nm}$ (See Fig. S8) centered at $3.5 \mathrm{~nm}$ supporting the existence of mesopores and macropores. In fact, the mesopores and macropores are formed due to aggregation of nanosheets because the single crystal nanosheets are nonporous [49]. Such organized porous structures might be 
extremely useful in photocatalysis because they possess efficient transport pathways to reactant and product molecules.

\subsection{UV-Visible spectra of $\mathrm{rGO}^{-\mathrm{TiO}_{2}}$ and $\mathrm{Au}-\mathrm{rGO}-\mathrm{TiO}_{2}$ nanocomposites}

The optical absorption property of bare $\mathrm{TiO}_{2}$ (rGO0T) and rGOXT samples measured with diffuse reflectance UV-Vis spectroscopy (DRUVS) are demonstrated in Fig. 8. The rGO0T sample shows the absorption in the UV-region which is the characteristic feature of $\mathrm{TiO}_{2}$ aroused due to the electron transitions from $\mathrm{O}_{2 \mathrm{p}} \rightarrow \mathrm{Ti}_{3 \mathrm{~d}}$ level [25]. The addition of $\mathrm{GO}$ onto the surface of $\mathrm{TiO}_{2}$ induced the change of the optical property of $\mathrm{TiO}_{2}$. The change in the optical property is well reflected in DRUVS spectra of all rGOXT samples through a broad absorption in the entire visible range because of the presence of graphenic carbons. The visible absorption background of rGOXT is increased with increasing the GO content because of the restoration of the $\pi$-electron conjugation within rGO sheets after hydrothermal reduction [50]. The absorption edge of rGOXT was red-shifted by 10-40 nm compared with that of pure $\mathrm{TiO}_{2}(\mathrm{rGO} 0 \mathrm{~T})$ indicating a narrowing of the band gap of $\mathrm{TiO}_{2}$. This implies that GO with various oxygen containing functional groups (see the FTIR spectra shown in Fig. S9) forms a surface complex with $\mathrm{TiO}_{2}$ nanoparticles. Recently, it is reported that the hydroxylated fullerene (or fullerol)- $\mathrm{TiO}_{2}$ complex and carbon-doped $\mathrm{TiO}_{2}$ composites absorbs visible light due to transfer of charge onto the surface of complex/composites [51,52].

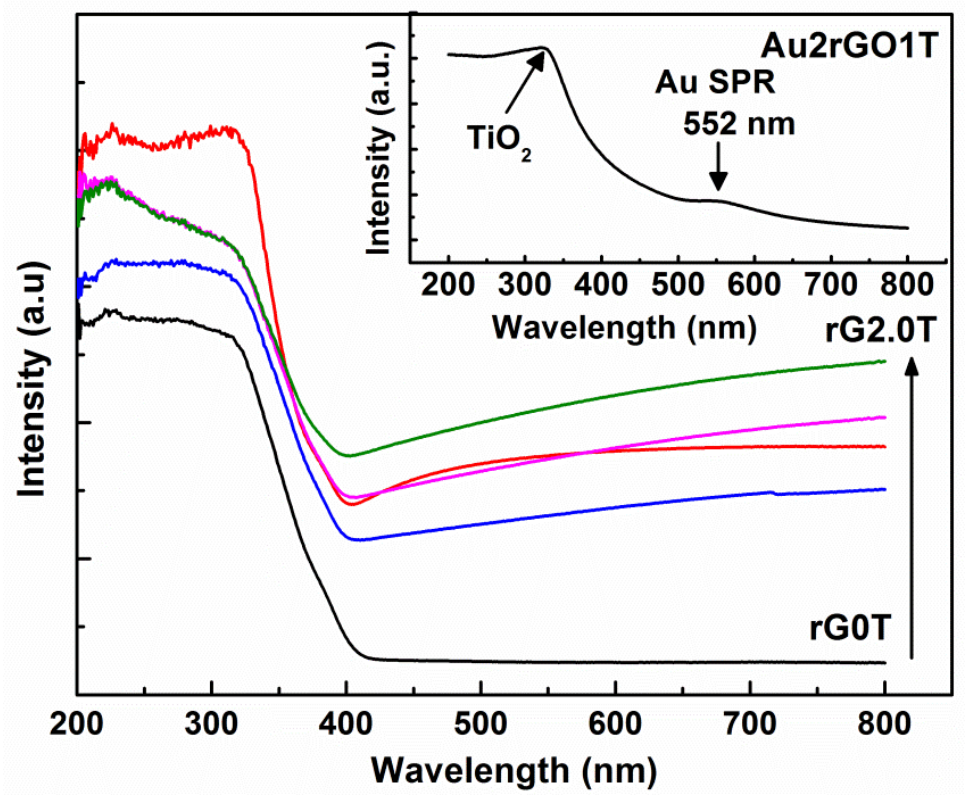

Figure 8: UV-Visible spectrum of $\operatorname{rGOXT}$ (where $\mathrm{X}=0,0.25,0.5,1.0$ and 2.0) samples. 


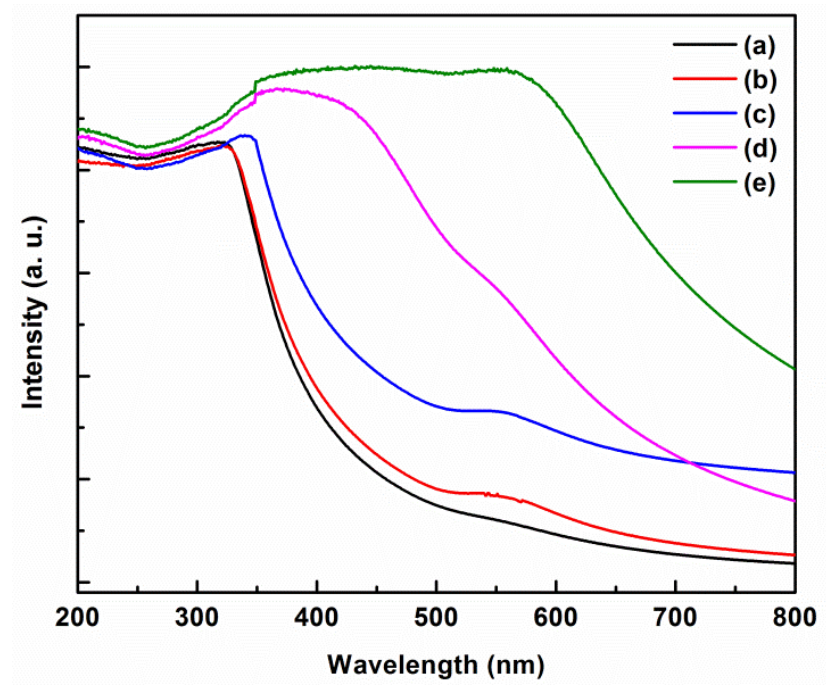

Figure 9: UV-Visible spectra of Au of (a) 0.5 (b) 1.0 (c) 2.0 (d) 5.0 and (f) $8.0 \mathrm{wt} \%$ loaded rGO1T samples.

A similar charge-transfer complex can be formed between the $\mathrm{rGO}$ and $\mathrm{TiO}_{2}$ surface. As a result of the surface complexation, the induced surface charge transfer in $\mathrm{rGO} / \mathrm{TiO}_{2}$ leads to the red shift of DRUVS compared with bare $\mathrm{TiO}_{2}$ because of the acidic functional groups present on $\mathrm{GO}$ (see Fig. S9). Furthermore, the DRUVS spectra of Au loaded rG1T samples are shown in Fig. 9. The plasmonic peak is observed around $552 \mathrm{~nm}$, indicating the presence of Au nanoparticles in the $\mathrm{Au}$ loaded rGO1T samples. A significantly enhancement in the absorption in the visible is observed. The enhancement in absorption band is ascribed due to the plasmonic resonance of metallic $\mathrm{Au}$ nanoparticles aroused from the collective oscillations of the free conduction band electrons induced by the incident electromagnetic radiation on Au nanoparticles [53]. The absorbance intensified and redshifted with increasing Au loading due to formation of bigger Au particles as observed in TEM images (Fig. 6) [54].

\subsection{Photo-catalytic Hydrogen evolution from plasmonic active photocatalyst}

Photo-catalytic hydrogen $\left(\mathrm{H}_{2}\right)$ evolution activities on reduced $\mathrm{GO}$ and its composite samples were evaluated through irradiation by High Pressure Hg Lamp in UV-Visible region in presence of methanol as a scavenger. Fig. 10 demonstrates the $\mathrm{H}_{2}$ evolution value of the rGOXT composites. In a controlled reaction, $\mathrm{H}_{2}$ evolution was almost negligible in the absence of photocatalyst whereas in the presence of photocatalyst in solution, a significant $\mathrm{H}_{2}$ evolution was detected. It indicates the photocatalytic activity was happening due to presence of the photocatalyst. In pure $\mathrm{TiO}_{2}(\mathrm{rGO} 0 \mathrm{~T})$, the photocatalytic activity is observed to be very low, i.e. $0.56 \mathrm{mmol}\left(\right.$ i.e $112 \mu \mathrm{molh}^{-1}$ ). The low activity is due to the formation of fast recombination between conduction band (CB) electrons and valance band (VB) 
holes and a fraction of the electrons and holes participate in the photo-catalytic reaction [55,56]. Also, the presence of a large over potential in the production of $\mathrm{H}_{2}$ on the $\mathrm{TiO}_{2}$ surface and the fast backward reaction (recombination of hydrogen and oxygen into water) make $\mathrm{TiO}_{2}$ inactive in photo-catalytic water splitting in the absence of graphene.

However, the $\mathrm{TiO}_{2}$ modified by small amount of graphene (rGO0.5T) shows considerable enhancement in the $\mathrm{H}_{2}$ production rate, i.e. 1.8 fold $(1.1 \mathrm{mmol})$ in comparison to pure $\mathrm{TiO}_{2}(\mathrm{rGO}$ T). The further increment in the amount of graphene sheets accelerates the $\mathrm{H}_{2}$ production and reached a maximum of $1.34 \mathrm{mmol}$ (i.e, $268 \mu \mathrm{molh}^{-1}$ ), i.e. 2.4 fold over rGO1T as shown in Fig. 10. Hence, the influence of graphene in photo-catalytic activity reasonably reflects with the enhancement in the $\mathrm{H}_{2}$ production. The enhancement in the $\mathrm{H}_{2}$ evolution in presence of graphene in $\mathrm{TiO}_{2}$ could be due to excellent electron accepting and transferring capability, and the capacity to restrain the recombination of the photo-excited electrons and holes effectively. It has been reported that the two-dimensional $\pi$ conjugation structure of graphene sheets facilitates the transfer of photo-induced electrons and can act as an excellent electron acceptor $[57,58]$.

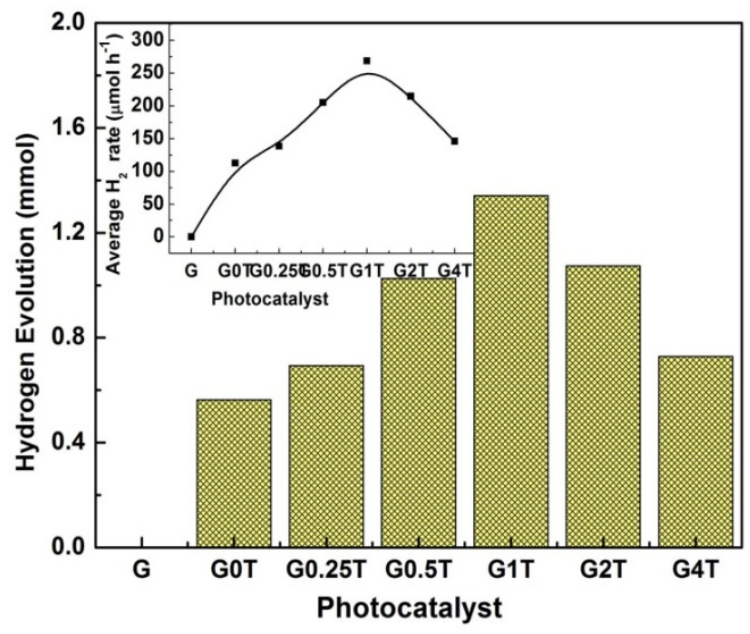

Figure 10: Photo-catalytic activity of photocatalyst for $\mathrm{H}_{2}$ evolution from methanol aqueous solution under UV-Visible light irradiation.

A further increase in graphene content leads to a reduction of the photo-catalytic activity. Hence, in the present study, the critical or optimum value for good photo-catalytic activity is $1.0 \mathrm{wt} \%$ of graphene with $\mathrm{TiO}_{2}$. The graphene content $2.0 \mathrm{wt} \%$ shows a drastic decrease in photo-catalytic activity in comparison to that of rGO1T. This is probably due to the fact that the excess graphene screens the active sites on the surface of the $\mathrm{TiO}_{2}$ photocatalyst and shields them from incident light. The TEM images in Fig. 5 (e and $\mathrm{f}$ ) shows the screening of $\mathrm{TiO}_{2}$ particles surface from rGO. The 
shielding prevents the photons absorption onto the surface of the $\mathrm{TiO}_{2}$ resulting a rapid reduction in the $\mathrm{H}_{2}$ production rate $[59,60]$. No appreciable $\mathrm{H}_{2}$ evolution was detected with graphene as photocatalyst under the same photo-catalytic reaction conditions and it suggests that bare graphene is not active for photo-catalytic $\mathrm{H}_{2}$ production under these experimental conditions. The results from this work and from the past reports suggest that the loading of graphene onto the $\mathrm{TiO}_{2}$ surface is very important to decide the optimal quantity of graphene for $\mathrm{H}_{2}$ production $[55,61]$.

In order to further enhance the capacity of $\mathrm{H}_{2}$ evolution using photocatalyst, the plasmonic $\mathrm{Au}$ as a co-catalyst was loaded onto the optimal photo-catalytically active rGO1T photo-catalysts. The $\mathrm{H}_{2}$ generating capability of these photo-catalysts was investigated in the same conditions. Fig. 11 shows the photo-catalytic activity of the Au co-catalyst loaded rGO1T (AuYrGO1T, where Y = 0.5, 1.0, 2.0, 3.0, 4.0, 5.0, and $8.0 \mathrm{wt} \%$ ) photo-catalysts. In Au0.5rGO1T sample, the $\mathrm{H}_{2}$ evolution value is $7 \mathrm{mmol}$ (i.e. $1.4 \mathrm{mmolh}^{-1}$ ) which is 5.2 folds higher than $\mathrm{rGO} 1 \mathrm{~T}$ as shown in Fig. 10. The maximum value of $\mathrm{H}_{2}$ production was achieved $12 \mathrm{mmol}$ (i.e. $2.4 \mathrm{mmolh}^{-1}$ ) in Au2rGO1T. On other hand, the Au contents above $2.0 \mathrm{wt} \%$ gradually decreases the $\mathrm{H}_{2}$ evolution activity.

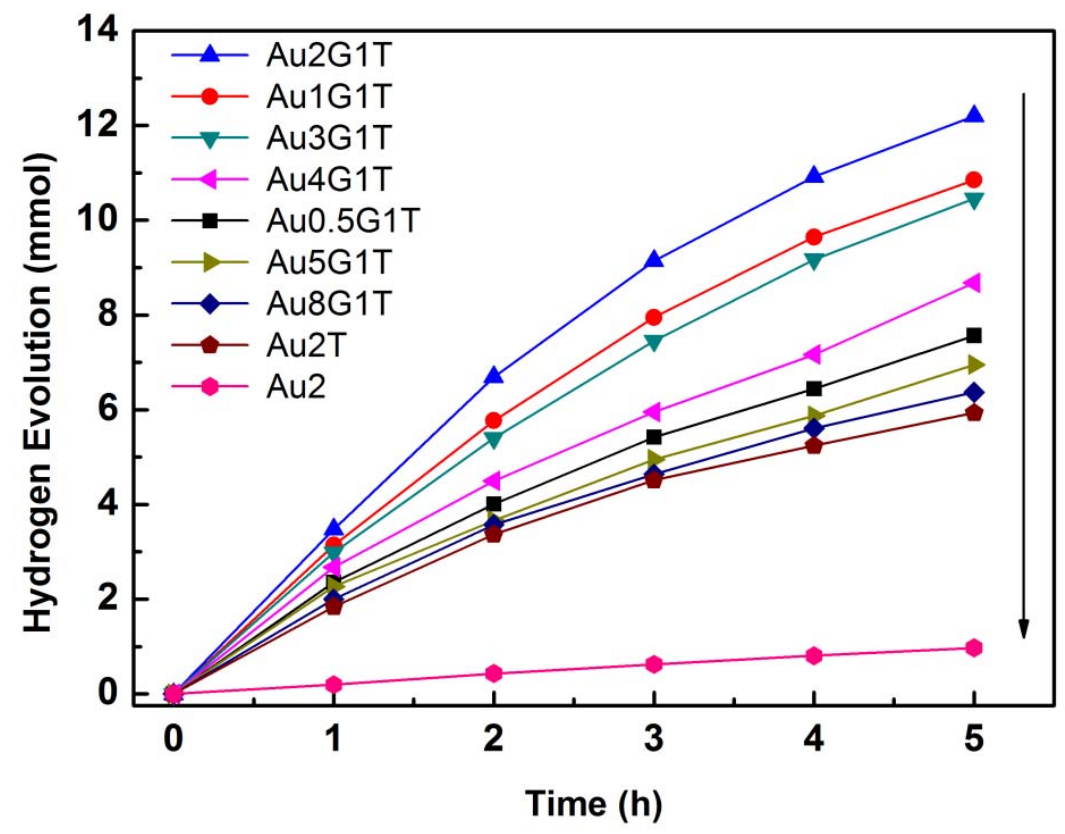

Figure 11: Hydrogen evolution through plasmonic active $\mathrm{Au}$ loaded rGO1T photo-catalysts from methanol aqueous solution under UV-visible light.

Hence, it is observed that the $\mathrm{H}_{2}$ evolution activity was dramatically increased with increasing the Au contents up to the optimal value of $2.0 \%$. This optimal value of the Au co-catalyst increases the trapping site for the carriers like graphene due to quantized charge effect. The trapping of carriers leads 
the longer life time for the interfacial charge transfer [55-58]. The process involves the transfer of photo generated electrons from the $\mathrm{CB}$ of $\mathrm{TiO}_{2}$ to the co-catalysts such as graphene and $\mathrm{Au}$, and the holes were scavenged by methanol in the $\mathrm{VB}$ of $\mathrm{TiO}_{2}$. Hence, electrons and holes are efficiently separated. However, the further increasing the Au loading on rGO1T results in a decrease of the in $\mathrm{H}_{2}$ rate. This is probably due to increase in the opacity and light scattering (see Fig. 11), leading to a decrease of irradiation passing through the reaction suspension solution. Other possible explanations might be: (i) the partial blockage of the $\mathrm{TiO}_{2}$ surface active sites due to excessive $\mathrm{Au}$ or reduction in average distance between trapping sites with increasing the number of the Au clusters confined within a particle and (ii) deterioration of the catalytic properties of Au metal nanoparticles due to their size enlargement $[55,62,63]$. The formation of the Au cluster or agglomeration of $\mathrm{Au}$ nanoparticles on $\mathrm{TiO}_{2}$ surface is well observed in TEM images in Fig. 6 (d-f). Therefore, it is not surprising that the photocatalytic activity of rGO1T samples having Au content more than $2.0 \mathrm{wt} \%$ are lower. With higher Au content, there should be an inverse cosine dependence on the reciprocal of loading since the loaded metal particles merged together and the total periphery began to shrink [55]. The major reaction steps in this photo-catalytic water splitting mechanism under UV-Visible light irradiation are summarized through following mechanism.

$$
\begin{gathered}
\text { Reduce Graphene(rGO)/Au/TiO } 2 \stackrel{h v}{\rightarrow} \mathrm{rGO} / \mathrm{Au}\left(e^{-}\right) / \mathrm{TiO}_{2}\left(h^{+}\right) \\
\mathrm{rGO} / \mathrm{Au}\left(e^{-}\right)+2 \mathrm{H}^{+} \rightarrow \mathrm{rGO} / \mathrm{Au}+\mathrm{H}_{2} \uparrow \\
\mathrm{nTiO}_{2}\left(h^{+}\right)+\mathrm{CH}_{3} \mathrm{OH}+6 \mathrm{OH}^{-} \rightarrow \mathrm{nTiO}_{2}+\mathrm{CO}_{2}+5 \mathrm{H}_{2} \mathrm{O}
\end{gathered}
$$

\subsection{Charge transfer process in $\mathrm{Au} / \mathrm{Graphene} \mathrm{TiO}_{2}$ photocatalyst}

The co-catalysts such as plasmonic $\mathrm{Au}$ and graphene improve the charge separation and suppress the recombination of excited photogenerated carriers, and it results in the enhancement in $\mathrm{H}_{2}$ evolution. Figure 12 demonstrates the charge separation and $\mathrm{H}_{2}$ evolution process. The whole process can be described as follows: it is well documented that the noble metal or metal ion doped semiconductor composites exhibit negative shift in the Fermi level which implies a higher degree of electron accumulation in $\mathrm{Au}$ decorated $\mathrm{TiO}_{2}[56,64]$. Thus, such shift in the Fermi level improves the energetics of the composite system and enhances the efficiency of interfacial charge-transfer process. This is associated with a considerable enhancement of the electric near-field. This peculiar activity is strongly related to their size and shape dependent surface charge oscillation known as surface plasmon resonance (SPR) in presence of light irradiation $[65,66]$. Here, the electrons in $\mathrm{TiO}_{2}$ are excited from the VB to the CB by UV light irradiation. The excited electrons then migrate to the Au nanoparticle 
decorated on $\mathrm{TiO}_{2}$, subsequently the SPR effect (see Fig. 9) induced by appropriate visible light irradiation boost the energy intensity of trapped electrons resulting in the photo-catalytic activity enhancement [67].

Furthermore, the incorporation of $\mathrm{GO}$ with $\mathrm{TiO}_{2}$ creates the $\mathrm{p}-\mathrm{n}$ junction which also considerably improves the separation of photogenerated charges. The photogenerated holes are scavenged by methanol, and the electrons are excited to the $\mathrm{CB}$. The electrons transferred from the $\mathrm{CB}$ of $\mathrm{TiO}_{2}$ are injected into the reduced graphene in a graphene/ $\mathrm{TiO}_{2}$ system because the graphene/graphene- redox potential is slightly lower than the $\mathrm{CB}$ of $\mathrm{TiO}_{2}[61,68]$. Graphene has a high charge carrier transfer and mobility due to $\pi$-conjugate structure and hence the Au nanoparticles dispersed on the graphene sheet can also accept electrons and act as active sites to react with adsorbed $\mathrm{H}^{+}$ions for $\mathrm{H}_{2}$ evolution. In addition, some conduction electrons of $\mathrm{TiO}_{2}$ likely transfer directly to the $\mathrm{Au}$ nano-clusters deposited on the surface of $\mathrm{TiO}_{2}$ semiconductor by ohmic interconnection or to carbon atoms on the graphene sheets, the electrons then react with the adsorbed $\mathrm{H}^{+}$ions to form $\mathrm{H}_{2}$. Thus, the synergetic effect between the two co-catalysts, plasmonic Au nanoparticles and graphene can effectively suppress photogenerated charge recombination, enlarge the active adsorption sites and reaction space, and consequently enhance the photo-catalytic activity for $\mathrm{H}_{2}$ evolution.

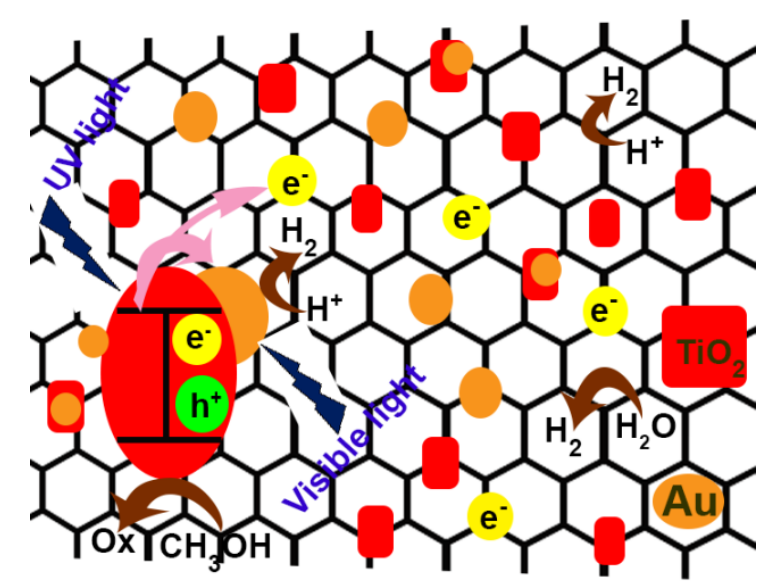

Figure 12: Charge transfer process in $\mathrm{Au} /$ graphene/ $\mathrm{TiO}_{2}$ photo-catalyst.

\section{Conclusion}

In summary, plasmonic active, $\mathrm{Au}$ loaded, graphene/ $\mathrm{TiO}_{2}$ composite photo-catalysts were developed. The SPR on the metal-loaded photo-catalysts can be an important way to use the full spectrum in sunlight for solar energy harvest, especially for wide bandgap materials, such as $\mathrm{TiO}_{2}$. Thus, both photon energies of UV and visible light can be absorbed and converted to chemical energy, 
i.e., $\mathrm{H}_{2}$ via water splitting. The optimal value of graphene and $\mathrm{Au}$ content was determined to be 1.0 and $2.0 \mathrm{wt} \%$, respectively, and the corresponding hydrogen evolution rate enhanced by $268 \mu \mathrm{molh}^{-1}$ and 2.4 mmolh ${ }^{-1}$, respectively, compared to pure $\mathrm{TiO}_{2}$. The synergic effect between the co-catalysts Au and graphene sheets can efficiently accept and transport the electrons from the excited semiconductor, suppress charge recombination, improve interfacial charge transfer processes, and provide much more active adsorption sites and photo-catalytic reaction centers, which consequently enhanced the photocatalytic $\mathrm{H}_{2}$ production activity. The Au nanoparticles are playing a role of electron acceptor due to the extra electromagnetic field provided by its SPR phenomenon.

\section{Acknowledgments}

We thank Dr. Bret N. Flanders, Dr. Daniel L. Boyle and Dr Leila Maurmann for their help to get Raman spectra, TEM images and FTIR respectively. We also thank to DST, New Delhi, Govt. of India, for providing opportunity to visit KSU under BOYSCAST fellowship.

\section{Corresponding author}

*Centre for Nanotechnology, Central University of Jharkhand, Brambe, Ranchi-835205, Jharkhand, India,

E-mail: gpsinghcuj@gmaol.com; gajendra.singh@cuj.ac.in

S: Supplementary Information

\section{References:}

1. Paracchino A, Laporte V, Sivula K, Grätzel M and Thimsen E 2011 Nat. Mater. 10456

2. Hou Y D, Abrams B L, P. Vesborg C K, Björketun M E, Herbst K, Bech L, Setti A M, Damsgaard C D, Pedersen T, Hansen O, Rossmeisl J, Dahl S, Nørskov J K, and Chorkendorff I 2011 Nat. Mater. 10, 434

3. Kudo A and Miseki Y 2009 Chem. Soc. Rev. 38253

4. Maeda K, Xiong A K, Yoshinaga T, Ikeda T, Sakamoto N, Hisatomi T, Takashima M, Lu D L, Kanehara M, Setoyama T, Teranishi T and Domen K 2010 Angew. Chem., Int. Ed. 494096

5. Zhang J, Yu J G, Zhang Y M, Li Q and Gong J R 2011 Nano Lett. 114774

6. Armaroli N and Balzani V 2007 Angew. Chem. Int. Ed. 4652

7. Dau H, Limberg C, Reier T, Risch M, Roggan S and Strasser P 2010 Chem. Cat. Chem. 2724

8. $\quad$ M. Grätzel 2001 Nature 414338

9. Fujishima A, and Honda K 1972 Nature 23837 
10. Zhang Xiao-Yan, Li Hao-Peng, Cui Xiao-Li and Lin Yuehe 2010 J. Mater. Chem. 20, 2801

11. Murdoch M, Waterhouse G I N, Nadeem M A, Metson J B, Keane M A, Howe R F, Llorca J and Idriss H. 2011 Nat. Chem. 3489

12. Yu J G and Ran J R 2011 Energy Environ. Sci. 41364

13. Carp O, Huisman C L and Reller A, 2004 Prog. Solid State Chem. 3233

14. Khan Z, Khannam M, Vinothkumar N, Deb M and Qureshi M 2012 J. Mater. Chem. 2212090

15. Novoselov K S, Geim A K, Morozov S V, Jiang D, Zhang Y, Dubonos S V, Grigorieva I V and Firsov A A 2004 Science 306666

16. Geim A K and Novoselov K S 2007 Nat. Mater. 6183

17. Geim A K 2009 Science 3241530

18. Lv X-J, Zhou S-X, Zhang C, Chang H-X, Chena Y and Fu W-Fu 2012 J. Mater. Chem. 22, 18542

19. Wu Z S, Ren W, Wen L, Gao L, Zhao J, Chen Z, Zhou G, Li F and Cheng H M 2010 ACS Nano 43187

20. $\mathrm{Ng}$ Y H, Iwase A, Kudo A and Amal R 2010 J. Phys. Chem. Lett. 12607

21. Li Y, Wang H, Xie L, Liang Y, Hong G and Dai H 2011 J. Am. Chem. Soc. 1337296

22. Yeh T F, Syu J M, Cheng C, Chang T H and Teng H 2010 Adv. Funct. Mater. 202255

23. Kowalska E, Remita H, Colbeau-Justin C, Hupka J and Belloni J 2008 J. Phys. Chem. C 112 1124

24. Subramanian V, Wolf E and Kamat P V 2004 J. Am. Chem. Soc. 1264943

25. Zhang L, Yu J C, Yip H Y, Li Q, Kwong K W, Xu A W and Wong P K 2003 Langmuir 19 10372

26. Gallo A, Marelli M, Psaro R, Gombac V, Montini T, Fornasiero P, Pievo R and Dal Santo V 2012 Green Chem. 14330

27. Yeh Y-C, Creran B and Rotello V M 2012 Nanoscale 41871

28. Hummers W S and Offeman R E 1958 J. Am. Chem. Soc. 801339

29. Kuo Y T, Frye C D, Ikenberry M and Klabunde K J 2013 Catalysis Today 19915

30. Kuo Y T and Klabunde K J 2012 Nanotechnology 23294001

31. Zhang H, Lv X J, Li Y M, Wang Y and Li J H 2010 ACS Nano 4380

32. Si Y C and Samulski E T 2008 Chem. Mater. 206792

33. Nepal A, Singh G P, Flanders B N and Sorensen C M 2013 Nanotechnology 24245602

34. Xiang Q J, Yu J G and Jaroniec M 2011 J. Phys. Chem. C 1157355

35. Yu J G, Ma T T and Liu S W 2011 Phys. Chem. Chem. Phys. 133491 
36. Yu J G, Ma T T, Liu G and Cheng B 2011 Dalton Trans. 406635

37. Yu J G, Fan J J and Cheng B 2011 J. Power Sources 1967891

38. Stankovich S, Dikin D A, Piner R D, Kohlhaas K A, Kleinhammes A, Jia Y, Wu Y, Nguyen S T, and Ruoff R S 2007 Carbon 451558

39. Lambert T N, Chavez C A, Hernandez-Sanchez B, Lu P, Bell N S, Ambrosini A, Friedman T, Boyle T J, Wheeler D R and Huber D J 2009 J. Phys. Chem. C 11319812

40. Vasu K S, Chakraborty B, Sampath S and Sood A K 2010 Solid State Commun. 1501295

41. Ferrari A C, Meyer J C, Scardaci V, Casiraghi C, Lazzeri M, Mauri F, Piscanec S, Jiang D, Novoselov K S, Roth S, and Geim A K 2006 Phys. Rev. Lett. 97187401

42. Meyer J C, Geim A K, Katsnelson M I, Novoselov K S, Booth T J and Roth S 2007 Nature 446 60

43. Parker J C and Siegel R W 1990 Appl. Phys. Lett. 57943

44. Li Hexing, Bian Zhenfeng, Zhu Jian, Huo Yuning, Li Hui, and Lu Yunfeng 2007 J. Am. Chem. Soc. 1294538

45. Zhang H., Chen S., Quan X., Yu H. T. and Zhao H. M. 2011 J. Mater. Chem 2112986.

46. Akhavan O 2010 ACS Nano 44174

47. Sing K S W, Everett D H, Haul R A W, Moscou L, Pierotti R A, Rouquerol J, and Siemieniewska T 1985 Pure Appl. Chem. 57603.

48. Kruk M and Jaroniec M 2001 Chem. Mater. 133169

49. Rouquerol F, Rouquerol J, and Sing K 1999 Adsorption by Powders and Porous Solids: Principles, Methodology and Applications, Academic Press, San Diego

50. Li D, Muller M B, Gilje S, Kaner R B and Wallace G G 2008 Nat. Nanotechnol. 3101

51. Park Y, Singh N J, Kim K S, Tachikawa T, Majima T and Choi W 2009 Chem.-Eur. J. 1510843

52. Sakthivel S and Kisch H 2003 Angew. Chem. Int. Ed. 42, 4908

53. Yonezawa T, Matsune H and Kunitake T 1999 Chem. Mater. 1133

54. Jensen T R and Duyne R P V 1999 J. Phys. Chem. B 1032394

55. Chen J-J, Wu J C S, Wu P C and Tsai D P 2011 J. Phys. Chem. C 115210

56. Choi H, Chen W T, and Kamat P V 2012 ACS Nano 64418

57. Zhang H, Lv X J, Li Y M, Wang Y and Li J H 2010 ACS Nano 4380

58. Yu J G, Wang W G, Cheng B and Su B L 2009 J. Phys. Chem. C 1136743

59. Yu J G, Hai Y and Jaroniec M 2011 J. Colloid Interface Sci. 357223

60. Yu J G, Y. Hai and Cheng B 2011 J. Phys. Chem. C 1154953

61. Xiang Q, Yu J and Jaroniec M 2011 Nanoscale 33670 
62. Sreethawong T and Yoshikawa S 2005 Catal. Commun. 6, 661

63. Yu Z and Chuang S 2008 Appl. Catal. B: Environ. 83277

64. M. Jakob, H. Levanon and P. V. Kamat, Nano letter, 2003, 3, 353-358.

65. Merlen A, Gadenne V, Romann J, Chevallier V, Patrone L and Valmalette J C 2009 Nanotechnology 201

66. Wu D J, Xu X D and Liu X J 2008 Solid State Commun. 148163

67. Awazu K, Fujimaki M, Rockstuhl C, Tominaga J, Murakami H, Ohki Y, Yoshida N and Watanabe T 2008 J. Am. Chem. Soc. 130, 1676

68. Wang X, Zhi L J and Mullen K 2008 Nano Lett. 8323 